\title{
Imaging Modalities for Assessment of Treatment Response to Nonsurgical Hepatocellular Carcinoma Therapy: Contrast-Enhanced US, CT, and MRI
}

\author{
Yasunori Minami Masatoshi Kudo \\ Department of Gastroenterology and Hepatology, Kinki University Faculty of Medicine, Osaka, Japan
}

\section{Key Words}

Hepatocellular carcinoma - Radiofrequency ablation .

Transcatheter arterial chemoembolization

\begin{abstract}
Tumor response and time to progression have been considered pivotal for surrogate assessment of treatment efficacy for patients with hepatocellular carcinoma (HCC). Recent advancements in imaging modalities such as contrast-enhanced ultrasound (US), computed tomography (CT), and magnetic resonance imaging (MRI) are playing an important role in assessing the therapeutic effects of HCC treatments. According to some HCC clinical guidelines, post-therapeutic evaluation of HCC patients is based exclusively on contrast-enhanced dynamic imaging criteria. The recommended techniques are contrast-enhanced CT or contrastenhanced MRI. Contrast-enhanced US is employed more in the positive diagnosis of HCC than in post-therapeutic monitoring. Although contrast enhancement is an important finding on imaging, enhancement does not necessarily depict the same phenomenon across modalities. We need to become well acquainted with the characteristics of each modality, including not only contrast-enhanced CT and MRI but also contrast-enhanced US. Many nonsurgical treatment options are now available for unresectable HCC, and accurate assessment of tumor response is essential to achieve favorable outcomes. For the assessment of successful radiofrequency ablation (RFA), the achievement of a sufficient ablation margin as well the absence of tumor vascular enhancement is essential. To evaluate the response to transcatheter arterial chemoembolization (TACE), enhanced tumor shrinkage is relied on as a measure of antitumor activity. Here, we give an overview of the current status of imaging assessment of $\mathrm{HCC}$ response to nonsurgical treatments including RFA and TACE.

Copyright $@ 2015$ S. Karger AG, Basel

Masatoshi Kudo, MD, PhD

Department of Gastroenterology and Hepatology,

Kinki University Faculty of Medicine

377-2 Ohno-higashi, Osaka-sayama, Osaka 589-8511 (Japan)

Tel. +81 723660221 (Ext. 3525), E-Mail m-kudo@med.kindai.ac.jp
\end{abstract}

KARGER 125 


\section{Introduction}

Hepatocellular carcinoma (HCC) is the sixth most common neoplasm and the third most frequent cause of cancer deaths. Surgical resection is regarded as a standard treatment for HCC patients [1]; however, the majority of HCC patients are not suitable for curative resection at the time of diagnosis because of large tumor size, multifocal disease, vascular involvement, extrahepatic spread, or poor liver function, among others [2-7]. Therefore, various nonsurgical treatment options have been developed in the effort to provide for patients with unresectable HCC. Local ablative techniques are increasingly used for minimally invasive treatment, and radiofrequency ablation (RFA) is currently performed widely due to its ease of use, safety, and effectiveness for managing unresectable HCC in patients with cirrhosis [8-14]. Transcatheter arterial chemoembolization (TACE) is the current standard of care for patients presenting with multinodular HCC with relatively preserved liver function, no cancer-related symptoms, and no evidence of vascular invasion or extrahepatic spread [15-21].

Monitoring tumor response to therapy is imperative for the clinical management of cancer patients, and accurate assessment of tumor response is essential for favorable outcomes. For HCC patients, imaging techniques such as contrast-enhanced US, CT, and MRI are used to diagnose HCC $[22,23]$ and to assess therapeutic effects [24-26]. However, these techniques employ different principles to generate images, and the types and doses of contrast agents are also different. Although contrast enhancement is an important finding on imaging, enhancement does not necessarily depict the same phenomenon across modalities. We therefore need to be familiar with the findings for each modality to evaluate the success of treatment, detect residual or recurrent tumors, and diagnose new lesions. In this review, we focus our discussion on the imaging assessment of HCC response to nonsurgical treatment including RFA and TACE.

\section{Response Evaluation Criteria}

The endpoint in cancer research is overall survival. Nonetheless, tumor response and time to progression have been considered pivotal for surrogate assessments of efficacy. In 2000, the European Association for the Study of the Liver (EASL) recommended measuring the change in the area of tumor enhancement on contrast-enhanced imaging as the optimal method to assess treatment response [27]. Introduced in 2008 as an amendment of the Response Evaluation Criteria in Solid Tumors (RECIST), the modified RECIST (mRECIST) [28] and the Response Evaluation Criteria in Cancer of the Liver (RECICL) [29] focus on the viable (enhanced on dynamic studies) tumoral components to assess the response of HCC to locoregional or antiangiogenic treatment. mRECIST, which is based on the unidimensional measurement of the enhanced portions of target tumors, is simple and easy to apply in clinical practice. According to some HCC clinical guidelines, post-therapeutic evaluation of HCC patients is based exclusively on contrast-enhanced dynamic imaging criteria. The recommended techniques are contrast-enhanced CT or contrast-enhanced MRI. However, there are cases (e.g., infiltrative tumors, heterogeneous necrosis) and situations (e.g., after ablation) in which the mRECIST criteria are difficult or impossible to apply [30]. Other imaging techniques such as angiography, contrast-enhanced US, and positron emission tomographyCT are considered to be controversial. It is worth mentioning that their roles have been explored more in the positive diagnosis of HCC than in post-therapeutic monitoring. 


\section{Imaging Assessment of Tumor Response}

\section{Radiofrequency Ablation}

Among the risk factors for recurrence, tumor size, portal vein invasion, and intrahepatic metastasis are generally considered the major causes of intrahepatic HCC recurrence after treatment. Several studies have addressed the relationship between micrometastases/microvascular invasion of HCC cells and tumor size. Okusaka et al. reported that 19\% of HCC nodules of $3.0 \mathrm{~cm}$ or less in diameter had satellite lesions that were not detected [31]. The reported frequency of microvascular invasion in patients with an HCC tumor of $2-3 \mathrm{~cm}$ is in the range of approximately 20-30\% [31-33]. Consequently, effective treatment is indicated not only by the absence of HCC tumor enhancement, but also by the safety margin. Nakashima et al. revealed that $59.1 \%$ of small HCC $\leq 3.0 \mathrm{~cm}$ in diameter had micrometastases within $5 \mathrm{~mm}$ of each micrometastatic lesion and its primary HCC [32]. For the RFA procedure to be considered technically successful, the tumor and at least a 5-mm safety margin must be included in the ablation zone [34]. The local recurrence rate differs markedly depending on whether a 5 -mm safety margin is secured. Kudo et al. reported that the local recurrence rate was $2.6 \%$ in HCC patients with a $\geq 5$-mm safety margin at 2 years after RFA, whereas it was $20.8 \%$ in HCC patients without such a safety margin $(p=0.01)$ [35].

Recurrence of tumors in the treated area or elsewhere is defined as reappearance of vascular enhancement. The ideal imaging interval is unknown, but initially a 3-4 month interval is commonly used to monitor HCC lesions after RFA therapy.

\section{Computed Tomography}

Contrast-enhanced CT is widely used for the evaluation of treatment response. Tissue contrast enhancement on CT depends on the blood flow, capillary permeability, rate of diffusion, and the extravascular extracellular space volume. In clinical practice, evaluation of the absence of tumor enhancement and the safety margin is based on a visual comparison of the pre- and post-RFA CT images by referring to specific landmarks such as hepatic vessels and the liver surface [35-37]. In addition, the safety margin has one more important role as security in avoiding the limitations of CT assessment due to partial volume effects.

Hyperemia in tissue surrounding the ablated lesion can represent an inflammatory reaction resulting from thermal injury. Peripheral rim enhancement resulting from reactive hyperemia is usually uniform in thickness and envelops the ablated lesion, whereas residual HCC demonstrates focal and irregular peripheral enhancement $[38,39]$.

Compared with RFA alone, the combination of RFA and TACE markedly increased the extent of induced coagulation of RFA [40]. Conventional Lipiodol-TACE offers another potential advantage for assessment of a subsequent RFA procedure. Lipiodol (Lipiodol Ultra-Fluide, Laboratoire Guerbet, Aulnay-Sous-Bois, France) is an oily contrast medium used in radiography. The ablative margin can be shown as the boundary between the high-density area of Lipiodol accumulation in HCC and the enhanced area of surrounding normal liver parenchyma. Therefore, the safety margin can be easily evaluated only by post-RFA dynamic CT images in HCC patients treated by RFA combined with TACE [41].

\section{Ultrasound}

US contrast mediums consist of gas-cored microbubbles that are encapsulated by a shell constructed of a lipid monolayer or cross-linked albumin. Contrast-enhanced echo signals contain significant energy components at higher harmonics from inside blood vessels. Contrast harmonic imaging can depict signals from microbubbles with a very slow flow and is a useful tool for depicting small residual HCCs or local recurrence of HCC [42-46]. Vilana et al. reported that the sensitivities for detection of residual tumors 1 day after RFA were $27 \%$ and $20 \%$ on contrast-enhanced US using SonoVue and contrast-enhanced CT, respectively [43]. 
Meanwhile, a double-contrast US technique using Sonazoid reinjection has been developed on the basis of two specific characteristics of Sonazoid: arterial flow images and Kupffer images in the post-vascular phase [47, 48]. Residual HCC can demonstrate a focal defect during the Kupffer phase and show hypervascular enhancement by the reinjection of Sonazoid. However, it is difficult to identify the safety margin on US in some cases. Zhou et al. found that contrast-enhanced US could not evaluate the safety margin in 34.8\% of HCC nodules because the tumor boundary could not be identified clearly by US after RFA [49].

\section{Magnetic Resonance Imaging}

MRI (conventional T1-weighted image (WI), T2WI, and dynamic contrast-enhanced imaging) for tumor response assessment following liver thermal ablation is considered the most accurate method for the early detection of residual/recurrent tumors. MRI evaluation of the absence of tumor enhancement and the safety margin is also based on a visual comparison of the pre- and post-RFA images by referring to specific landmarks of the liver. A hyperintense zone on non-enhanced T1WI within 2 days after RFA reflects the extent of the ablated region [50]. Functional imaging including diffusion-weighted MRI has the ability to provide unique insights into molecular water distribution within a tumor, and therefore indicate tumor viability at a cellular level [51]. Viable tumors after RFA appeared as hyperintense, and necrotic regions were recognized as hypointense areas on diffusion-weighted MRI. Kele et al. found that ablation site recurrences showed significantly lower apparent diffusion coefficient values than the ablation zone and normal liver parenchyma $\left(1.02 \times 10^{3}\right.$ $\mathrm{mm}^{2} / \mathrm{s}$ vs. $1.31 \times 10^{3} \mathrm{~mm}^{2} / \mathrm{s}$ ) [52]. Hepatocyte-specific MRI contrast agents were developed for the detection and characterization of focal liver lesions, and gadolinium-ethoxybenzyldiethylenetriamine pentaacetic acid (Gd-EOB-DTPA) is a contrast agent with the combined properties of a conventional non-specific extracellular contrast agent and a hepatocytespecific contrast agent. Hepatocyte-phase images help to distinguish vascular pseudolesions (e.g., those caused by arterioportal shunting, portal venule obstruction, nonportal splanchnic veins, or rib compression) from hypervascular tumors [53]. Makino et al. reported that Gd-EOB-DTPA-enhanced MRI enabled treatment evaluation in a significantly larger number of HCCs than CT did (86/92 [93.5\%] vs. 62/92 [67.4\%], p<0.05) [54].

\section{TACE}

Conventional TACE (c-TACE), involving administration of an anticancer agent-in-oil emulsion followed by embolic agents, is a popular technique, and Lipiodol accumulation in HCCs after TACE can be regarded as representing a necrotic area. Recently, drug-eluting beads (DEB) have provided an attractive alternative to iodized oil-based regimens [55]. Both c-TACE and DEB-TACE can induce direct tumor necrosis and demonstrate anticancer efficacy. Enhanced tumor shrinkage is relied on as a measure of antitumor activity. However, tumor response is not paralleled by a reduction in overall tumor load but rather by a reduction in viable tumor [29]. Therefore, response assessment of TACE is recommended; this can be achieved by performing contrast-enhanced imaging 1 month after initial treatment and at least every 3 months during follow-up [29].

Computed Tomography

CT is also commonly used as the standard imaging technique for evaluating the therapeutic response to TACE. Dense, uniform retention of Lipiodol in the tumor is a reliable surrogate marker for complete or near-complete tumor necrosis, and the pattern and distribution of Lipiodol in the tumor are useful for assessing the therapeutic effects of c-TACE (fig. 1). However, small vague areas of hypervascularity that represent arterial-portal shunts, commonly seen in patients with HCC, are a frequent cause of "pseudolesions" on CT, again 

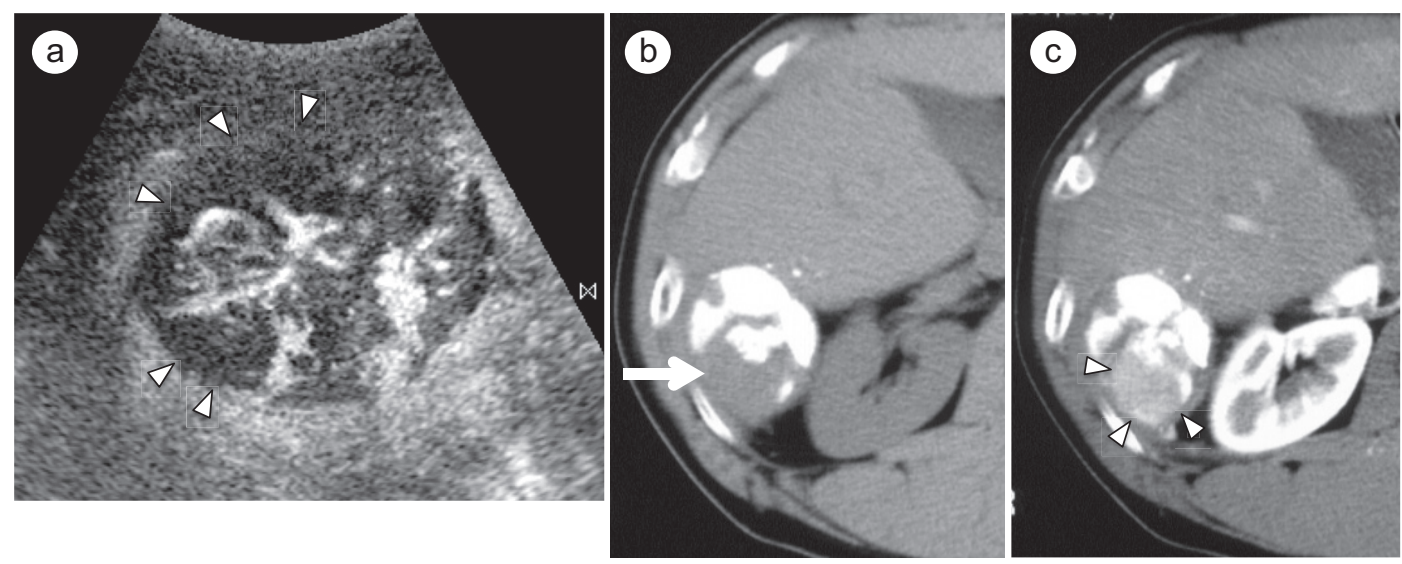

Fig. 1. A 64-year-old man with a 4-cm HCC in segment 6 that was treated with c-TACE. a Contrastenhanced US obtained 5 days after chemoembolization shows blood flow and avascular areas (arrowheads) in tumor during the arterial phase. b Plain CT scan obtained 1 week after treatment clearly shows defect of iodized oil accumulation (arrow) in tumor. c Arterial phase dynamic CT scan obtained at same time as Fig. $1 \mathrm{~b}$ clearly shows a partially enhancing area (arrowheads) corresponding to an area lacking Lipiodol accumulation.

limiting specificity. In addition, beam-hardening artifacts from the iodized oil can make it difficult to visualize marginal recurrences as well as residual viable tumor.

In patients treated with DEB-TACE, viable tumor is defined according to the uptake of contrast in the arterial phase of dynamic CT. The density, expressed in Hounsfield units (HU), is measured at CT examination both before and after treatment. The absence of significant differences of density between the phases is defined as indicating the presence of coagulative necrosis $[56,57]$.

Ultrasound

Contrast-enhanced US offers not only a very high sensitivity to contrast agents but also a high spatial resolution (fig. 1). Unlike CT imaging, contrast-enhanced US imaging is not influenced by Lipiodol retention. Xia et al. reported that the detection rates of positive enhancement with contrast-enhanced US and dynamic CT 1 week after TACE were 25 (58.1\%) of 43 lesions and 17 (39.5\%) of 43 lesions, respectively [58]. Contrast-enhanced US was significantly more sensitive than dynamic CT in depicting the residual tumor blood supply to HCCs 1 week after TACE ( $\mathrm{p}<0.01$; chi-squared test). Use of contrast-enhanced US permits the proper and early selection of patients who would benefit from additional focal therapy after TACE, as well as helping to guide focal ablation to the viable portion of HCC $[59,60]$. However, contrastenhanced US has technical limitations imposed by body habitus and the difficulty involved in accessing lesions near the hemidiaphragm. Additionally, contrast-enhanced US examinations used to be performed on a solitary mass or on a dominant mass in patients with multiple lesions.

\section{Magnetic Resonance Imaging}

Lipiodol causes variable signal intensity changes on unenhanced MRI, and is difficult to detect accurately. Recently, diffusion-weighted MRI is increasingly used in addition to conventional unenhanced and enhanced MRI. Diffusion-weighted MRI is known to have limitations such as a relatively low signal-to-noise ratio. However, it may offer additional value in evaluation and follow-up because diffusion-weighted MRI can provide information about molecular tissue characteristics [52]. 
Gadolinium diethylenetriaminepentaacetic acid (Gd-DTPA) is the most commonly used MRI contrast agent. It has an extracellular distribution and behaves similarly to the iodinated contrast agents used in CT. The presence of gadolinium can strongly influence the relaxation properties of nearby protons, leading to changes in tissue contrast. Consequently, enhanced areas in the embolization site on gadolinium-enhanced MRI presumably represent viable tumor [61, 62] but could also result from posttreatment granulation tissue [63]. Goshima et al. reported that sensitivity for the detection of local HCC recurrence after TACE was higher on gadolinium-enhanced MR imaging (82\%) than on diffusion-weighted MR imaging $(60.7 \%)$ for two readers, in combination and separately $(\mathrm{p}<0.05)$ [64].

\section{Adverse Reactions}

Kobayashi et al. reported in their large-scale study that the prevalence of all adverse reactions to nonionic contrast media was $2 \%$ and that of severe reactions was $0.1 \%$ [65]. The vast majority of these reactions were mild, including rash/hives, itching, nausea with or without vomiting, cough, or lump in the throat, among others.

The total incidence of adverse reactions to contrast agents in MRI ranges between $2 \%$ and $4 \%$. Most frequent are minor, general reactions such as nausea, emesis, hives, and headache and local reactions such as skin irritation, itching, and coolness.

It should be noted that gadolinium chelates administered to patients with acute renal failure or severe chronic kidney disease can result in a syndrome of nephrogenic systemic fibrosis. Therefore, use of these contrast media is no longer recommended in these patients.

The adverse reaction rate of US contrast agents seems to be relatively low compared with the contrast agents used in CT or MRI. The incidence of contrast agent complications ranges from $0.014 \%$ to $0.077 \%$ [66]. The most frequently reported adverse events are diarrhea, headache, albuminuria, and rash.

\section{Conclusion}

Accurate assessment of tumor response with imaging modalities is essential for favorable outcomes. For successful RFA, the achievement of a sufficient ablation margin as well the absence of tumor vascular enhancement is essential. For TACE response evaluation, enhanced tumor shrinkage is relied on as a measure of antitumor activity. We need to become well acquainted with the characteristics of each modality, including contrast-enhanced US, $\mathrm{CT}$, and MRI, and careful comparison of imaging before/after therapy is critical for HCC patients treated with RFA or TACE.

\section{Disclosure Statement}

The authors declare that no conflict of interest exists. 


\section{References}

1 Mise Y, Sakamoto Y, Ishizawa T, Kaneko J, Aoki T, Hasegawa K, Sugawara Y, Kokudo N: A worldwide survey of the current daily practice in liver surgery. Liver Cancer 2013;2:55-66.

2 Minagawa M, Makuuchi M, Takayama T, Kokudo N: Selection criteria for repeat hepatectomy in patients with recurrent hepatocellular carcinoma. Ann Surg 2003;238:703-710.

3 Capussotti L, Muratore A, Massucco P, Ferrero A, Polastri R, Bouzari H: Major liver resections for hepatocellular carcinoma on cirrhosis: early and long-term outcomes. Liver Transpl 2004;10(Suppl 1):S64-S68.

4 Poon RT, Fan ST: Hepatectomy for hepatocellular carcinoma: patient selection and postoperative outcome. Liver Transpl 2004;10(Suppl 1):S39-S45.

5 Song TJ, Ip EW, Fong Y: Hepatocellular carcinoma: current surgical management. Gastroenterology 2004;127(Suppl 1):S248-S260.

6 Llovet JM, Schwartz M, Mazzaferro V: Resection and liver transplantation for hepatocellular carcinoma Semin Liver Dis 2005;25:181-200.

7 Lin S, Hoffmann K, Schemmer P: Treatment of hepatocellular carcinoma: a systematic review. Liver Cancer 2012;1:144-158.

8 Rossi S, Di Stasi M, Buscarini E, Cavanna L, Quaretti P, Squassante E, Garbagnati F, Buscarini L: Percutaneous radiofrequency interstitial thermal ablation in the treatment of small hepatocellular carcinoma. Cancer J Sci Am 1995;1:73-81.

9 Curley SA, Izzo F, Ellis LM, Nicolas Vauthey J, Vallone P: Radiofrequency ablation of hepatocellular cancer in 110 patients with cirrhosis. Ann Surg 2000;232:381-391.

10 Shiina S, Teratani T, Obi S, Sato S, Tateishi R, Fujishima T, Ishikawa T, Koike Y, Yoshida H, Kawabe T, Omata M: A randomized controlled trial of radiofrequency ablation with ethanol injection for small hepatocellular carcinoma. Gastroenterology 2005;129:122-130.

11 Llovet JM, Bruix J: Novel advancements in the management of hepatocellular carcinoma in 2008. J Hepatol 2008;48(Suppl 1):S20-S37.

12 Lencioni R, Crocetti L: Local-regional treatment of hepatocellular carcinoma. Radiology 2012;262:43-58.

13 Rossi S, Ravetta V, Rosa L, Ghittoni G, Viera FT, Garbagnati F, Silini EM, Dionigi P, Calliada F, Quaretti P, Tinelli C: Repeated radiofrequency ablation for management of patients with cirrhosis with small hepatocellular carcinomas: a long-term cohort study. Hepatology 2011;53:136-147.

14 Lin SM: Local ablation for hepatocellular carcinoma in Taiwan. Liver Cancer 2013;2:73-83.

15 Yamada R, Sato M, Kawabata M, Nakatsuka H, Nakamura K, Takashima S: Hepatic artery embolization in 120 patients with unresectable hepatoma. Radiology 1983;148:397-401.

16 Ohishi H, Uchida H, Yoshimura H, Ohue S, Ueda J, Katsuragi M, Matsuo N, Hosogi Y: Hepatocellular carcinoma detected by iodized oil. Use of anticancer agents. Radiology 1985;154:25-29.

17 Takayasu K, Shima Y, Muramatsu Y, Moriyama N, Yamada T, Makuuchi M, Hasegawa H, Hirohashi S: Hepatocellular carcinoma: treatment with intraarterial iodized oil with and without chemotherapeutic agents. Radiology 1987;163:345-351.

18 Matsui O, Kadoya M, Yoshikawa J, Gabata T, Arai K, Demachi H, Miyayama S, Takashima T, Unoura M, Kogayashi K: Small hepatocellular carcinoma: treatment with subsegmental transcatheter arterial embolization. Radiology 1993;188:79-83.

19 Takayasu K: Transarterial chemoembolization for hepatocellular carcinoma over three decades: current progress and perspective. Jpn J Clin Oncol 2012;42:247-255.

20 Lencioni R: Chemoembolization for hepatocellular carcinoma. Semin Oncol 2012;39:503-509.

21 Raoul JL, Gilabert M, Piana G: How to define transarterial chemoembolization failure or refractoriness: a European perspective. Liver Cancer 2014:3:119-124.

22 Murakami T, Tsurusaki M: Hypervascular benign and malignant liver tumors that require differentiation from hepatocellular carcinoma: key points of imaging diagnosis. Liver Cancer 2014;3:85-96.

23 Kudo M, Matsui O, Izumi N, Iijima H, Kadoya M, Imai Y, Okusaka T, Miyayama S, Tsuchiya K, Ueshima K, Hiraoka A, Ikeda M, Ogasawara S, Yamashita T, Minami T, Yamakado K, Liver Cancer Study Group of Japan: JSH consensus-based clinical practice guideline for the management of hepatocellular carcinoma: 2014 update by the Liver Cancer Study Group of Japan. Liver Cancer 2014;3:458-468.

24 Lee JM, Yoon JH, Joo I, Woo HS: Recent advances in CT and MR imaging for evaluation of hepatocellular carcinoma. Liver Cancer 2012;1:22-40.

25 Minami Y, Kudo M: Therapeutic response assessment of transcatheter arterial chemoembolization for hepatocellular carcinoma: ultrasonography, CT and MR imaging. Oncology 2013;84(Suppl 1):58-63.

26 Minami Y, Nishida N, Kudo M: Therapeutic response assessment of RFA for HCC: contrast-enhanced US, CT and MRI. World J Gastroenterol 2014;20:4160-4166.

27 Bruix J, Sherman M, Llovet JM, Beaugrand M, Lencioni R, Burroughs AK, Christensen E, Pagliaro L, Colombo M, Rodés J, EASL Panel of Experts on HCC European Association for the Study of the Liver: Clinical management of hepatocellular carcinoma. Conclusions of the Barcelona-2000 EASL conference. J Hepatol 2001;35:421-430.

28 Lencioni R, Llovet JM: Modified RECIST (mRECIST) assessment for hepatocellular carcinoma. Semin Liver Dis 2010;30:52-60.

29 Kudo M, Kubo S, Takayasu K, Sakamoto M, Tanaka M, Ikai I, Furuse J, Nakamura K, Makuuchi M: Response evaluation criteria in cancer of the liver (recicl) proposed by the liver cancer study group of Japan (2009 revised version). Hepatol Res 2010;40:686-692. 
30 Yaghmai V, Besa C, Kim E, Gatlin JL, Siddiqui NA, Taouli B: Imaging assessment of hepatocellular carcinoma response to locoregional and systemic therapy. AJR Am J Roentgenol 2013;201:80-96.

31 Okusaka T, Okada S, Ueno H, Ikeda M, Shimada K, Yamamoto J, Kosuge T, Yamasaki S, Fukushima N, Sakamoto M: Satellite lesions in patients with small hepatocellular carcinoma with reference to clinicopathologic features. Cancer 2002;95:1931-1937.

32 Nakashima Y, Nakashima O, Tanaka M, Okuda K, Nakashima M, Kojiro M: Portal vein invasion and intrahepatic micrometastasis in small hepatocellular carcinoma by gross type. Hepatol Res 2003;26:142-147.

33 Esnaola NF, Lauwers GY, Mirza NQ, Nagorney DM, Doherty D, Ikai I, Yamaoka Y, Regimbeau JM, Belghiti J, Curley SA, Ellis LM, Vauthey JN: Predictors of microvascular invasion in patients with hepatocellular carcinoma who are candidates for orthotopic liver transplantation. J Gastrointest Surg 2002;6:224-232, discussion 232.

34 Goldberg SN, Grassi CJ, Cardella JF, Charboneau JW, Dodd GD 3rd, Dupuy DE, Gervais D, Gillams AR, Kane RA, Lee FT Jr, Livraghi T, McGahan J, Phillips DA, Rhim H, Silverman SG, Society of Interventional Radiology Technology Assessment Committee: Image-guided tumor ablation: standardization of terminology and reporting criteria. J Vasc Interv Radiol 2005;16:765-778.

35 Kudo M: Local ablation therapy for hepatocellular carcinoma: current status and future perspectives. J Gastroenterol 2004;39:205-214.

36 Tateishi R, Shiina S, Ohki T, Sato T, Masuzaki R, Imamura J, Goto E, Goto T, Yoshida H, Obi S, Sato S, Kanai F, Yoshida H, Omata M: Treatment strategy for hepatocellular carcinoma: expanding the indications for radiofrequency ablation. J Gastroenterol 2009;44(Suppl 19):142-146.

37 Kim KW, Lee JM, Klotz E, Kim SJ, Kim SH, Kim JY, Han JK, Choi BI: Safety margin assessment after radiofrequency ablation of the liver using registration of preprocedure and postprocedure CT images. AJR Am J Roentgenol 2011;196:W565-572.

38 Limanond P, Zimmerman P, Raman SS, Kadell BM, Lu DS: Interpretation of CT and MRI after radiofrequency ablation of hepatic malignancies. AJR Am J Roentgenol 2003;181:1635-1640.

39 Kim SK, Lim HK, Kim YH, Lee WJ, Lee SJ, Kim SH, Lim JH, Kim SA: Hepatocellular carcinoma treated with radio-frequency ablation: spectrum of imaging findings. Radiographics 2003;23:107-121.

40 Kitamoto M, Imagawa M, Yamada H, Watanabe C, Sumioka M, Satoh O, Shimamoto M, Kodama M, Kimura S, Kishimoto K, Okamoto Y, Fukuda Y, Dohi K: Radiofrequency ablation in the treatment of small hepatocellular carcinomas: comparison of the radiofrequency effect with and without chemoembolization. AJR Am J Roentgenol 2003;181:997-1003.

41 Nishikawa H, Inuzuka T, Takeda H, Nakajima J, Sakamoto A, Henmi S, Matsuda F, Eso Y, Ishikawa T, Saito S, Kita R, Kimura T, Osaki Y: Percutaneous radiofrequency ablation therapy for hepatocellular carcinoma: a proposed new grading system for the ablative margin and prediction of local tumor progression and its validation. J Gastroenterol 2011;46:1418-1426.

42 Meloni MF, Goldberg SN, Livraghi T, Calliada F, Ricci P, Rossi M, Pallavicini D, Campani R: Hepatocellular carcinoma treated with radiofrequency ablation: comparison of pulse inversion contrast-enhanced harmonic sonography, contrast-enhanced power Doppler sonography, and helical CT. AJR Am J Roentgenol 2001;177:375-380.

43 Vilana R, Bianchi L, Varela M, Nicolau C, Sánchez M, Ayuso C, García M, Sala M, Llovet JM, Bruix J, Bru C, BCLC Group: Is microbubble-enhanced ultrasonography sufficient for assessment of response to percutaneous treatment in patients with early hepatocellular carcinoma? Eur Radiol 2006;16:2454-2462.

44 Kim CK, Choi D, Lim HK, Kim SH, Lee WJ, Kim MJ, Lee JY, Jeon YH, Lee J, Lee SJ, Lim JH: Therapeutic response assessment of percutaneous radiofrequency ablation for hepatocellular carcinoma: utility of contrast-enhanced agent detection imaging. Eur J Radiol 2005;56:66-73.

45 Salvatore V, Bolondi L: Clinical impact of ultrasound-related techniques on the diagnosis of focal liver lesions. Liver Cancer 2012;1:238-246.

46 Inoue T, Kudo M, Hatanaka K, Arizumi T, Takita M, Kitai S, Yada N, Hagiwara S, Minami Y, Sakurai T, Ueshima K, Nishida N: Usefulness of contrast-enhanced ultrasonography to evaluate the post-treatment responses of radiofrequency ablation for hepatocellular carcinoma: comparison with dynamic CT. Oncology 2013;84(Suppl 1):51-57.

47 Kudo M, Hatanaka K, Maekawa K: Newly developed novel ultrasound technique, defect reperfusion ultrasound imaging, using Sonazoid in the management of hepatocellular carcinoma. Oncology 2010;78(Suppl 1):40-45.

48 Kudo M, Hatanaka K, Kumada T, Toyoda H, Tada T: Double-contrast ultrasound: a novel surveillance tool for hepatocellular carcinoma. Am J Gastroenterol 2011;106:368-370.

49 Zhou P, Kudo M, Minami Y, Chung H, Inoue T, Fukunaga T, Maekawa K: What is the best time to evaluate treatment response after radiofrequency ablation of hepatocellular carcinoma using contrast-enhanced sonography? Oncology 2007;72(Suppl 1):92-97.

50 Khankan AA, Murakami T, Onishi H, Matsushita M, Iannaccone R, Aoki Y, Tono T, Kim T, Hori M, Osuga $\mathrm{K}$, Passariello R, Nakamura H: Hepatocellular carcinoma treated with radio frequency ablation: an early evaluation with magnetic resonance imaging. J Magn Reson Imaging 2008;27:546-551.

51 Vilgrain V: Advancement in HCC imaging: Diagnosis, staging and treatment efficacy assessments: Hepatocellular carcinoma: Imaging in assessing treatment efficacy. Journal of Hepato-biliary-pancreatic Sciences 2010;17:374-379.

52 Kele PG, van der Jagt EJ: Diffusion weighted imaging in the liver. World J Gastroenterol 2010;16:15671576. 
53 Yoon JH, Lee EJ, Cha SS, Han SS, Choi SJ, Juhn JR, Kim MH, Lee YJ, Park SJ: Comparison of gadoxetic acidenhanced MR imaging versus four-phase multi-detector row computed tomography in assessing tumor regression after radiofrequency ablation in subjects with hepatocellular carcinomas. J Vasc Interv Radiol 2010;21:348-356.

54 Makino Y, Imai Y, Igura T, Hori M, Fukuda K, Sawai Y, Kogita S, Fujita N, Takehara T, Murakami T: Comparative evaluation of three-dimensional Gd-EOB-DTPA-enhanced MR fusion imaging with CT fusion imaging in the assessment of treatment effect of radiofrequency ablation of hepatocellular carcinoma. Abdom Imaging 2015;40:102-111.

55 Lammer J, Malagari K, Vogl T, Pilleul F, Denys A, Watkinson A, Pitton M, Sergent G, Pfammatter T, Terraz S, Benhamou Y, Avajon Y, Gruenberger T, Pomoni M, Langenberger H, Schuchmann M, Dumortier J, Mueller C, Chevallier P, Lencioni R, PRECISION V Investigators: Prospective randomized study of doxorubicin-elutingbead embolization in the treatment of hepatocellular carcinoma: results of the PRECISION V study. Cardiovasc Intervent Radiol 2010;33:41-52.

56 Liu Q, Li A, Sun S, Luo R, Chen F: The true role of mRECIST guideline: does it really estimate viable tumor or merely improve accuracy in hepatocellular carcinoma response evaluation? J BUON 2014;19:398-405.

57 Boatta E, Corona M, Cannavale A, Fanelli F, Cirelli C, de Medici L: Endovascular treatment of hepatocellular carcinoma with drug eluting microparticles (DC-Beads): CT evaluation of response to the treatment. Indian J Radiol Imaging 2013;23:126-133.

58 Xia Y, Kudo M, Minami Y, Hatanaka K, Ueshima K, Chung H, Hagiwara S, Inoue T, Ishikawa E, Kitai S, Takahashi S, Tatsumi C, Ueda T, Hayaishi S, Maekawa K: Response evaluation of transcatheter arterial chemoembolization in hepatocellular carcinomas: the usefulness of sonazoid-enhanced harmonic sonography. Oncology 2008;75(Suppl 1):99-105.

59 Minami Y, Kudo M, Kawasaki T, Kitano M, Chung H, Maekawa K, Shiozaki H: Transcatheter arterial chemoembolization of hepatocellular carcinoma: usefulness of coded phase-inversion harmonic sonography. AJR Am J Roentgenol 2003;180:703-708.

60 Kono Y, Lucidarme O, Choi SH, Rose SC, Hassanein TI, Alpert E, Mattrey RF: Contrast-enhanced ultrasound as a predictor of treatment efficacy within 2 weeks after transarterial chemoembolization of hepatocellular carcinoma. J Vasc Interv Radiol 2007;18:57-65.

61 Ito K, Honjo K, Fujita T, Matsui M, Awaya H, Matsumoto T, Matsunaga N, Nakanishi T: Therapeutic efficacy of transcatheter arterial chemoembolization for hepatocellular carcinoma: MRI and pathology. J Comput Assist Tomogr 1995;19:198-203.

62 Kubota K, Hisa N, Nishikawa T, Fujiwara Y, Murata Y, Itoh S, Yoshida D, Yoshida S: Evaluation of hepatocellular carcinoma after treatment with transcatheter arterial chemoembolization: comparison of Lipiodol-CT, power Doppler sonography, and dynamic MRI. Abdom Imaging 2001;26:184-190.

63 De Santis M, Alborino S, Tartoni PL, Torricelli P, Casolo A, Romagnoli R: Effects of lipiodol retention on MRI signal intensity from hepatocellular carcinoma and surrounding liver treated by chemoembolization. Eur Radiol 1997;7:10-16.

64 Goshima S, Kanematsu M, Kondo H, Yokoyama R, Tsuge Y, Shiratori Y, Onozuka M, Moriyama N: Evaluating local hepatocellular carcinoma recurrence post-transcatheter arterial chemoembolization: is diffusionweighted MRI reliable as an indicator? J Magn Reson Imaging 2008;27:834-839.

65 Kobayashi D, Takahashi O, Ueda T, Deshpande GA, Arioka H, Fukui T: Risk factors for adverse reactions from contrast agents for computed tomography. BMC Med Inform Decis Mak 2013;13:18.

66 Dijkmans PA, Visser CA, Kamp 0: Adverse reactions to ultrasound contrast agents: is the risk worth the benefit? Eur J Echocardiogr 2005;6:363-366. 